\title{
De la publicación de la fotografía a la fotografía publicada: en torno a los orígenes decimonónicos publicitaria
}

\author{
Dr. Diego Coronado e Hijón
}

Profesor Asociado del Departamento de Comunicación Audiovisual, Publicidad y Literatura.Universidad de Sevilla

\begin{abstract}
«Muchos de los deseos del individuo ya no son ni tan siquiera evidentes para él mismo. Sólo se le presentan cuando son sintetizados, elaborados y nutridos por la publicidad y la técnica de ventas, y éstas a su vez, se han convertido en una de nuestras profesiones más importantes e inteligentes. Pocas personas a comienzos del siglo XIX tenían necesidades de un agente de publicidad que les dijese qué era lo que querían» (Galbraith 1958: 28).
\end{abstract}

El desarrollo de la Fotografía decimonónica está claramente afianzado en los manuales de Fotografía en torno a un discurso documental, informativo o periodístico, pero casi nunca unido al discurso publicitario. Sin embargo, si la Publicidad surge a mediados del siglo XIX, paralelamente al discurrir gestacional de la imagen fotográfica, por qué no podemos hablar de una Fotopublicidad decimonónica. El reto que nosotros aquí nos hemos propuesto se centra entonces, en rastrear las bases estéticas, tecnológicas e ideológicas de un supuesto desarrollo foto-publicitario puesto al descubierto y a lo largo del siglo XIX; es decir, desde el primer momento en que se produce el encuentro conjunto entre la Fotografía y la Publicidad.

En definitiva, nuestra hipótesis de partida en este artículo puede resumirse bajo la siguiente pregunta: ¿Existió una Fotopublicidad anterior a la Fotopublicidad actual que todos hoy (re)conocemos? Y si es así, ¿cuáles fueron sus códigos, su retórica, y su estética?. Pero esta pregunta plantea ya un presupuesto conceptual de partida. Y es saber primero qué entendemos nosotros por Fotopublicidad, para poder luego determinar cuándo ha cristalizado un mensaje Fotopublicitario. En este sentido, entiendo de manera muy genérica, que existe Fotopublicidad, en todo discurso donde al trabajo de la imagen -exclusivamente fotográfica- se aúna la retórica Publicitaria, ya sea, con fines de promoción Comercial (si se pretende persuadir): caso éste de las 'Cartes de Visite' de Disdèri, -como tendremos ocasión de ver; con fines de promoción Cultural (si se pretende convencer): caso claro éste de la primera fotografía de documentación y de patrimonio artístico auspiciada por la política expansionista de los gobiernos coloniales del siglo XIX. O por último, con fines institucionales, si lo que se pretende es funcionalizar una conducta): $y$ aquí podría situarse el papel desempeñado por toda la primera fotografía de prensa, y muy especialmente, la fotografía de guerra, con Roger Fenton a la cabeza.

Debate teórico pues, en torno a la fotografía -tanto desde el punto de vista histórico como desde el de su concepción semiótica del estatuto que se debe asignar a su imagen-, que es a la vez el origen mismo de nuestra tesis principal en este trabajo: la necesidad de volver a las fuentes escritas y prácticas de la fotografía decimonónica como sustento de la que luego será una de las prácticas más aceptadas y asumidas por parte del sistema capitalista de las democracias occiden- 
tales: la industria de la fotopublicidad que se desarrolla paulatinamente a lo largo de la primera mitad del siglo $X X, y$ que terminaría de aflorar definitivamente tras la segunda guerra europea Por tanto el alcance de estos nuestros objetivos no quisiera aquí servir sino para arrojar una tenue luz que posibilite la multiplicación de nuevos estudios teóricos sobre la fotografía publicitaria, desde su vinculación primera y primaria con el origen histórico de la fotografía. Sirva como botón de muestra de esta deficiencia investigadora, los escasos tratados que sobre la fotografía de publicidad se han escrito hasta la fecha desde una perspectiva teórica arraigada en sus orígenes histórico-técnicos y en la esencia de imagen obtenida por contacto químico, lo que a la postre reportará el sustrato conceptual más necesario para entender la fuerza de convicción y de movilización que obtiene la fotografía dentro de su incardinación en el discurso publicitario.

\section{La fotografía decimonónica: entre el Arte y la Industria}

esde que se proclamase de manera oficial la invención del procedimiento fotográfico ante la Cámara de Diputados, el 3 de julio de 1839; y después de que el mismo fuera sancionado ante las Academias de Ciencias y Letras en la célebre fecha del 19 de agosto de 1839, la Fotografía no ha dejado de ser un instrumento, al servicio por igual de las Artes y de las Ciencias. En las propias transcripciones escritas que nos han llegado del discurso que el diputado François Aragò pronunciara acerca de las virtudes y los logros que el nuevo procedimiento prometía para la ciencia decimonónica en auge y para toda la nueva cultura contemporánea derivada de ella, puede leerse esta doble adscripción y esta ambivalencia del medio entre su concepción como herramienta al servicio de la ciencia y su configuración como dispositivo artístico capaz de configurar imágenes reveladoras de una nueva realidad estética. No puede extrañarnos entonces, la recurrencia, el consejo y la rúbrica de uno de los más afamado y reconocido de los historiadores del arte, miembro del Instituto y profesor de la École de Beaux-Arts, Paul Delaroche -lo que hoy denominaríamos un informe pericial-, con la que hace acompañar su discurso el diputado y secretario perpetuo de la Academia francesa:

«En una nota redactada a petición nuestra, este célebre pintor [Paul Delaroche] declaró que el procedimiento de Daguerre: 'lleva muy lejos la perfección de ciertas condiciones esenciales en el arte, y que se convertirá para los pintores, incluso para los más hábiles, en un modelo de observación y estudio'. -Y más adelante continúa el propio Delaroche-: 'lo que caracteriza a los dibujos fotográficos es que están dotados de un acabado precioso no imaginable [...]. La corrección de las líneas y de las formas es tan completa como posible sea imaginar; y al mismo tiempo, se le encuentra un gran modelado y un parecido tan rico de tonos como de efectos [...]». En este punto, el diputado vuelve a retomar su discurso en primera persona para concluir: «Tras haber combatido con excelentes argumentos las opiniones de aquéllos que imaginan que la fotografía perjudicaría a cientos de artistas, 
el señor Delaroche concluye el informe con la siguiente declaración: 'En resumen, el admirable descubrimiento del señor Daguerre es un gran servicio que se rinde a las artes' «(Aragò, 1839. Recogido en: CNP, 1987. Traducción nuestra).

Tenemos por lo tanto delimitado así el origen embrionario de la cuestión principal que aquí nos ocupa, y que como vemos preocupó por igual desde el comienzo, tanto a intelectuales -científicos y filósofos-, como a los propios artistas -pintores y escritores- de la época en su intento por encasillar y definir el sitio que debería ocupar en lo sucesivo el procedimiento fotográfico: entre su concepción como herramienta al servicio de la ciencia y su configuración como dispositivo artístico capaz de configurar imágenes reveladoras de una nueva realidad estética. Inquietud intelectual pues, sobre la que aquí nosotros quisiéramos volver, pues aun cuando la fotografía ha sido desde entonces motivo de cientos de artículos y de publicaciones centradas sobre esta misma cuestión, su estatuto en tanto que dispositivo de representación ha quedado anclado a su condición de imagen artística de espaldas a su condición científica más esencial: su carácter de imagen de representación (de representación, sí; pero de representación científica) obtenida por mediación de la impresión química de aquéllo que en la naturaleza hay de más sustancial, los rayos lumínicos (en el caso de que hablemos de procedimientos que prescindan de la cámara oscura); o bien de su carácter de dispositivo ópticoquímico (en el caso de que hablemos de procedimientos que hagan uso de la cámara oscura y sus derivados); supeditada en fin a las leyes científicas de su mecanismo de base.

Desde este momento, una primera concepción de la fotografía comienza a aflorar, en tanto que dispositivo o artefacto científico ineludible, de la que ya no podremos prescindir cuando vengamos a referirnos a la consagración de su estatuto representacional. El propio Aragò había aconsejado la pronta incorporación de la fotografía en campos científicos tan distintos como la arqueología, la observación microscópica, la astronomía, la conservación y restauración de obras de arte, o la historia natural. Y un decenio después, las crónicas de la primera Exposición Universal, celebrada en el Crystal Palace de Londres, resultan significativas en cuanto a las obligaciones encomendadas todavía a la fotografía: «...provocar armonía entre el arte y la industria», (En: Pohlmann, 1993: 496-513). Testimonio que aclara bastante bien cuál era la consideración del medio en la época. Y sería precisamente por parte de las necesidades demandadas por esta misma maquinaria industrial como la fotografía alcance pronto el mundo editorial y de la divulgación seriada. Cuatro años después, no resultará casual que la fundación de la Sociedad Francesa para la Fotografía (SFP), coincida con la celebración de la primera Exposición Universal celebrada en París, la del año de 1855. Una vez más quedó demostrada la relevancia que la fotografía iba a tener sobre los avances de la 
ingeniería para el nuevo siglo en el proceso de industrialización: desde la documentación fotográfica de la reconstrucción del Crystal Palace, emprendida por Henry Delamotte (1853-1854), hasta el inventario de las primeras y ruidosas locomotoras construidas en Manchester a cargo de James Mudd.

El personaje que mejor representa una segunda concepción de la fotografía, entendida esta vez como obra de arte, a la par que como instrumento reproductor en beneficio de una industria, sería Gustave Le Gray. Las instantáneas de nubes y de olas de este pintor, que había colgado los pinceles tras conocer el invento de la fotografía, terminarían ejerciendo una decisiva influencia sobre toda la pintura de naturaleza, -desde los realistas (Courbert), hasta los primeros pintores de la llamada escuela de Barbizon (Corot)-. Dedicado en cuerpo y alma al ejercicio y la defensa de la fotografía artística, en 1850 escribiría uno de los más importantes tratados estéticos sobre fotografía del momento. Tratado que debido a su importante acogida, hubo de ser reeditado sucesivamente en cuatro ocasiones en París, desde 1851 hasta 1854, con el título de: «Nouveau Traité pratique des photographies sur papier et sur vèrre». El punto de vista argüido por Le Gray era el defendido por todos en la época; esto es, potenciar la organización industrial del procedimiento a fin de que pueda obtenerse lo antes posible importantes beneficios económicos de su reproducción editorial, a la par que ofrecer ante el nuevo público masivo de clase media los nuevos conocimientos derivados de la ciencia. Pero a diferencia de otros fotógrafos comerciales contemporáneos suyos como Eugène Disdèri, o los hermanos Meyer et Pierson, Le Gray expresa su deseo de que «en lugar de caer bajo el dominio de la industria, o del comercio, entre en el del arte, su verdadero sitio». (Recogido por Rouillé \& Lemagny en, 1981: 44). Se trata por tanto de la postura encontrada que tiende a defender el uso industrial de la fotografía, pero sin menoscabo de su consideración como objeto artístico' ${ }^{1}$.

En torno a estas dos posiciones, -los partidarios por un lado, de la fotografía concebida como bien de uso comercial y con fines lucrativos privados, y los partidarios por otro lado, de la fotografía concebida en tanto que imagen que se debía primero a su condición de obra de arte-, es como se plantea el primer debate teórico una vez se hubo superado el primer decenio de los años cuarenta, dedicado necesariamente a consolidar la fragilidad de un invento embrionario que terminaría calando e imponiéndose en la sociedad burguesa europea sólo por su capacidad de obtener pingües beneficios económicos merced a su condición de imagen comercial de fuerte consumo privado -individual- y social -colectivo-. El destino

1 El subtítulo de la primera revista sobre fotografía que se edita en Francia dedicada exclusivamente a debatir El subtítulo de la primera revista sobre fotografía que se edita en Francia dedicada exclusivamente a debatir
estos temas, parece tener también muy claro la ineludible doble personalidad del procedimiento: «La Lumière: reviste de la photographie, des Beaux Arts, de la Heliographie et des Sciences». Al frente de la misma se sitúa Ernest Lacan, abanderado de su uso en tanto que imagen al servicio de la iniciativa privada
con claros intereses económicos y comerciales. 
sufrido por dos de los fotógrafos más importantes del momento, deja entrever y anticipa la solución que nosotros aquí proponemos a este debate: nos referimos en un caso al triste final que le estaba reservado al propio Le Gray, quien prefirió renunciar a la práctica fotográfica antes que abjurar de su condición de artista creador de imágenes funcionalmente estéticas; o, en el extremo más claro, el fin que le aguardaba al maestro de los retratistas del siglo XIX, el 'Gran Nadar', quien para mantener con vida sus intenciones artísticas, hubo de acometer toda una estrategia mercadotécnica en la venta de sus retratos, para hacer frente a la competencia de la tarjeta de visita y la proliferación del retrato comercial.

A partir de lo visto hasta aquí, podemos comenzar a vislumbrar una poderosa causa que subyace detrás del irrefrenable proceso de crecimiento y aceptación que obtendría la fotografía en la sociedad contemporánea, desde sus orígenes decimonónicos: detrás de ello se sitúa creemos, una poderosa industria económica, generada por la emergente demanda de fabricación y divulgación del retrato individual (en el caso de la economía de la empresa privada y burguesa); así como de imágenes procedentes de tierras inexploradas; y que se yergue a lo largo de todo el siglo XX, (en el caso de ala economía de empresa de orden institucional o política). En ambos casos, no situamos ante la Imagen por excelencia de la nueva época de la contemporaneidad, demandada por un nuevo público y un nuevo mercado, ávidos de la información y del contenido expresivo que comporta el nuevo sistema de registro de lo real. Poder de información y de atracción, que desde muy pronto sería colonizado por las primeras empresas del capitalismo incipiente, en el siglo XIX.

\section{Nièpce y la Heliografía en el origen de la Impresión Ilustrada}

El debate en torno a si una imagen obtenida por medio de procedimientos óptico-químicos, y sin la intervención de la mano del hombre podría ser considerada como una obra de arte, o por el contrario debía reducir sus funciones a la de fiel servidora de las ciencias y de las artes, no cristalizaría hasta la década de los años 50. No obstante, durante los primeros tanteos y experimentos alternativos de toda índole que flanquean la historia oficiosa del medio puede rastrearse esta misma inseguridad en el caminar de los primeros años de la fotografía atraída antes por la facilidad de consecución de unos recursos económicos derivados de su primera explotación industrial a manos de la industria de la edición seriada. Nièpce había iniciado sus investigaciones con la ayuda de la Cámara Oscura, obteniendo pruebas del natural o 'Puntos de Vista'. Sin embargo, tal como ocurrirá en el caso de Talbot, desalentado por la borrosidad de la imagen, y la lentitud del proceso, reorientaría sus esfuerzos a partir de 1817 hacia la consecución de un cliché fotográfico que se situara en la base de posteriores copias obtenidas a partir del original, la Heliografía. A partir de aquí, se inicia su contribución más importante para la fotopublicidad, pues con este 
procedimiento nos situamos a medio camino entre la Litografía y el Heliograba$\mathrm{do}^{2}$.

La Heliografía precisaba de un dibujo original o grabado a línea que engrasado con aceite se colocaba encima de una superficie recubierta de una mezcla a base de betún de judea y espliego, o esencia de lavanda; la particularidad que presenta este compuesto es que a la luz se endurecía, de manera que permitía que aquéllas partes transparentes del grabado creasen una dura capa para impedir que la superficie de la copia trasparentase el original; por el contrario, las líneas dibujadas del original impedían que el betún se endureciera. De esta forma, y tras un proceso posterior de lavado con aceite de toda la superficie reproductora, el betún endurecido por su exposición a la luz permitía dibujar las mismas marcas rayadas que el original presentaba pero en tonos invertidos: esto es, donde antes había líneas negras que delimitaban el contorno del dibujo, aparecían ahora los surcos blancos a modo de negativo de su original. El dibujante así no tendría que depender del grabador, y él mismo podría rellenar con tinta estos surcos y claros para obtener tantas copias como el propio material permitiese ${ }^{3}$.

Pero lo que verdaderamente estaba proponiendo Nièpce con este procedimiento que quedaría eclipsado tras los fastos de la proclamación de la daguerrotipia, era la continuación de esa larga carrera tecnológica hacia la reproducción de la imagen que se había iniciado desde el siglo XV, -con el grabado xilográfico primero y con el grabado calcográfico sobre metal después-; que continuará con los procedimientos de impresión con fotograbados procedentes del siglo anterior -desde Bewick, hasta William Blake-, y que culminaría hacia los primeros años de nuestro siglo, con la grabación en un mismo bloque de la imagen y el texto, a partir de un cliché fotográfico -origen tecnológico pues de la fotopublicidad contemporánea ${ }^{4}$.

Sin embargo Nièpce, -que nunca se había preocupado de hacer publicidad de sus investigaciones-, murió en silencio y sus descubrimientos permanecieron

2 En 1789, Alois Senefelder un músico segundón, se encontraba enfrascado en un procedimiento automático para registrar las notas ...Y en 1860, Thomas Bolton xilógrafo de segunda fila, tendrá la feliz idea de sensibilizar la superficie de su taco de madera para estampar sobre ella un registro fotográfico, como guía sobre el que poder dibujar su grabado. A partir de entonces, y durante el resto del siglo XIX, la ilustració de libros con imágenes seriadas desarrollaría inevitablemente este mismo proceso de estampación sobre alcaloides permannetes: bien, produciendo una matriz fotográfica sobre piedra (fotolitografía); o bien, sobre metal (heliograbado).

3 Sin embargo Nièpce, desfraudado por la necesida de conseguir una imagen directa sin la intervención del dibujante, volverí a lo que él mismo hab́a denomindo desde 1816, sus «Puntos de Vistas: piedres dibujante, volvería a lo que él mismo había denominado desde 1816, sus «Puntos de Vista». piedras y placas de metal recubiertas con betún, y preparadas en el interior de sus cámaras oscuras para capta directamente la imagen del exterior.

Dentro de esta misma línea tecnológica de evolución de la imagen seriada, no puede resultar extraño el hecho de que sea tras la primera guerra mundial, cuando comienza a reconocerse profesionalmente la figura del fotógrafo vinculado con exclusividad al ámbito de la publicidad, las revistas ilustradas y la imagen de moda. 
siendo olvidados para la comunidad, salvo para una persona: el pintor Jacques M. Daguerre. Desde entonces, y una vez que éste pensara divulgar en revistas especializadas sus daguerrotipos y ofrecérselos a los industriales e impresores de la época, lo hará haciendo uso de este mismo procedimiento, y de espaldas a la figura del propio Nièpce.

\section{El Sr. Daguerre, o la 'cara publicidad' en la fotografía decimonónica}

Jacques Mandé Daguerre era un pintor fracasado sin conocimientos científicos, y $\sin$ tan siquiera preparación intelectual alguna, a diferencia de lo que habían sido por el contrario sus contemporáneos, Nièpce y Talbot. A pesar de ello, -o quizás por ello mismo-, el Sr, Daguerre parecía estar tocado con la vitola del éxito desde los primeros días de su acercamiento a la fotografía, a juzgar por la rapidez con que supo granjerase el apoyo de todos: desde el apoyo incondicional mostrado por parte de los pintores de la Academia; así como el respaldo manifiesto declarado por parte de científicos de la talla de Jean-Baptiste Biot, Joseph-Louis Gay Lussac, Alexander Von Humboldt, del propio Aragò; hasta, la ayuda financiera prestada por el propio gobierno francés. Con todas estas muestras de solidaridad y de apoyo colectivo hacia su empresa, el Sr. Daguerre conseguiría ser elevado ante el mundo entero como el inventor de la fotografía, por encima incluso de sus propios predecesores en la materia y acreedores en igual medida de la paternidad del invento 5

Sus inicios en París están relacionados con uno de los más rentables espectáculos de masas de la época, el Diorama. Consistía éste, en una enorme sala cerrada con sillas dispuestas frente a un gran escenario, en el que a semejanza del actual cinematógrafo, el público podía presenciar sobre una pantalla blanca translúcida, imágenes combinadas de grandes cuadros en perspectiva que mediante el uso de un juego de luces y sombras cambiantes conseguía crear la máxima ilusión de realidad tridimensional con la ayuda de objetos interpuestos delante y/o detrás de las escenas pintadas e iluminadas. Las imágenes pintadas por Daguerre, eran imágenes captadas por la Cámara Oscura, y desde 1927 Daguerre pensará en la

5 Tras los éxitos y favores obtenidos por parte de Daguerre, tras la publicación oficial por parte del gobierno francés de su procedimiento fotográfico, se destapa la caja de pandora de los descubridores de este medio: Friederich Gerber, en Suiza; el reverendo J. B. Reade, en Gran Bretaña: F. Von Kobell y Carl Von Steinheil, en Alemania; Hans Thoger Winther, en Noruega; y Hercules Florence, en Brasil. Sin embargo, ninguna muestra gráfica de estos experimentos pioneros han sido encontrados, y todos desaparecerían de la memoria colectiva, víctimas solo de la falta de su propia campaña de autopromoción pública. Peor suerte correría aún el francés Hippolyte Bayard, de quien no sólo testimonios de sus positivos directos sobre papel, haciendo uso de una técnica a medio camino entre (la irreproductibilidad de) Daguerre y (la papel, haciendo uso de una técnica a medio camino entre (la irreproductibilidad de) Daguerre y (la indefinición de) Talbot, sino que figura en los anales de la fotografía como el autor que realiza por primer de instinto comercial e inteŕs de lucro, le apartaría definitivame de cuobier recompensa económica o nominativa. 
manera de fijar estas imágenes con el fin de ahorrar trabajo y aumentar su ilusión de realidad. A través de Louis Chevalier, óptico que proveía de lentes a Nièpce, consigue entrar en contacto con este último. De su facilidad para la retórica y de su don para la persuasión, da buena fe la carta manuscrita que el propio Nièpce escribiera a su hijo en setiembre de 1827 :

«He tenido frecuentes y prolongadas entrevistas con Daguerre. La reunión se prolongó tres horas... y la conversación sobre el tema que nos interesa es realmente interminable (...). Nada hevisto aquí que me impresionara tanto, ni me diera tanto placer como el Diorama. Fuimos guiados en ello por el señor Daguerre, y pudimos contemplar con toda comodidad, los magníficos tableaux allí expuestos (...). Estas representaciones son tan reales, hasta el ínfimo detalle, que uno llega a creer que está viendo la naturaleza rústica y salvaje, con toda la ilusión que pueden aportar el encanto de los colores y la magia del claro-oscuro. la ilusión es tan grande que uno se siente tentado a dejar la butaca, pasearse al aire libre y subir a la cima de la montaña. Te aseguro que no hay la menor exageración de mi parte» (Nièpce, 1827).

Dos años más tarde consigue un contrato de asociación con Nièpce, que a la postre resultaría decisivo, pues cuatro años después moría éste último sin haber dejado previamente por escrito relevancia patente de su autoridad en el proceso. Circunstancia que aprovecha el Sr. Daguerre para hacerse con la paternidad de sus investigaciones. En 1833, otro químico, el académico Jean Baptista Dumas, conocedor de sus experimentos, le aconseja el uso de vapores de mercurio para el revelado de la imagen latente; y sólo dos años más tarde, tenemos el ejemplo más antiguo del procedimiento que finalmente se publicaría con el nombre de Daguerrotipia: esto es, imagen única y directa, tal como había preocupado a Nièpce desde sus primeros ensayos con la heliografía.

A partir de ese momento, Daguerre hombre de negocios hábil y avispado, se encontró con el camino expedito para lanzarse a despertar una expectativa y a crear una demanda públicas, favorable a su descubrimiento apoyándose exclusivamente en lo que hoy denominaríamos una campaña de concienciación publicitaria, previa al lanzamiento de su producto. Mientras tanto, se cuidaría muchísimo de mantener en estricto silencio el secreto del procedimiento fotográfico, hasta tanto no convenciera al gobierno francés de que «...hasta la fecha, la física no había ofrecido una maravilla comparable a su invento», -tal como comentaba un periódico de la época. Son los momentos de la vida del 'inventor', que pasa ocupándose de organizar sesiones públicas y demostraciones, en los Salones del Ministerio del Interior y en el Conservatorio de Artes y Oficios; a la par que entra en conversaciones con agentes comerciales y embajadores de los principales países industrializados, como es el caso de Samuel B. Morse. Puede entenderse así el paralelismo 
existente entre la carta anterior escrita por Nièpce, y la que escribiera el inventor del telégrafo al 'New-Yor Observer', informando acerca de las posibilidades del daguerrotipo:

«No os podéis imaginar hasta qué grado de minuciosidad se registran los trazos. Lo que ninguna pintura o grabado puede lograr. Por ejemplo, recorriendo con la vista la imagen de una calle, se podía notar la presencia de una pancarta lejana, sobre la cual el ojo alcanzaba a distinguir las líneas existentes entre las letras; éstas resultaban demasiado pequeñas para ser percibidas directamente por nuestros ojos; pero gracias a la ayuda de una lupa poderosa cada letra, cada detalle era perfectamente legible (...)».

(Morse, 1839; traducción nuestra).

Finalmente, y ante las presiones de peligrosas voces extranjeras como era la del inglés Fox Talbot, el primero de junio de 1839 Daguerre contrata a un agente de patentes en Londres, y cuatro días más tarde, consigue que el Ministro del Interior francés oiga una descripción de su invento avalado por el informe del historiador del arte, Paul Delaroche. Sería así como finalmente Daguerre consigue la rúbrica del emperador Luis Felipe, al firmar el 7 de agosto de 1839, la ley aprobada en el Palacio del Instituto de la Academia. Con lo que además de ser reconocido Oficial de la Legión de Honor por el propio Luis Felipe, y de recibir la condecoración de numerosos jefes de estado extranjeros, reportaría a Daguerre una renta vitalicia millonaria, que sumará a los ingresos obtenidos de la venta de los mejores daguerrotipos que llevarán estampados su nombre a modo de imagen de marca; y todo ello, sin olvidar los pingües beneficios que obtiene de la publicación de los secretos de su procedimiento con el opúsculo titulado: «Historique et description du procédé du Daguerreotype et du Diorama», aparecido en más de treinta capitales repartidas por todo el mundo.

El daguerrotipo aparece como un procedimiento de muy difícil manipulación debido a la inconsistencia de sus componentes químicos, además de adolecer de graves problemas técnicos en cuanto a su legibilidad y presentación: por ejemplo, la imagen era perecedera, y debía ser protegida del aire y del roce del tacto si se quería evitar su degradación progresiva. Y lo que resultaba aún más lamentable, la imagen no consigue su multiplicación automática; ésta aparecía invertida, y sobre una superficie espejeante que hacía difícil su lectura a poco que los rayos de sol incidieran oblicuamente sobre la placa.

No obstante, y a pesar de estos inconvenientes, la moda de la daguerrotipia se extendería por París y por el resto de las metrópolis europeas como un reguero de pólvora prendida en los hilos de la campaña publicitaria levantada por un tal Sr. Daguerre, que había conseguido anular y silenciar al resto de las prácticas alternativas aparecidas durante todo el decenio de los años 40. Bajo el influjo de 
su promotor, el daguerrotipo (si exceptuamos las prácticas de los calotipistas y defensores de la fotografía como imagen de arte más convencidos: Charles Negre y el priopio Gustave Le Gray en París; y David O. Hill en Escocia), dominará frente a procedimientos alternativos más ambiciosos como los de Talbot o Hippolyte Bayard, haciendo uso -eso sí- de las dos prácticas más extendidas desde el comienzo de la fotografía: el Retrato -de uso privado y consumo individual-, y el Paisaje o la foto de paisaje -destinado a la colectividad y de uso preferentemente estatal.

Nos han quedado testimonios escritos de la expectación que despertaría ante el público moderno, un invento cuyo lanzamiento oficial había venido precedido de una campaña de publicidad a escala internacional que duraba ya ocho meses. Marc-Antoine Gaudin, autor en 1841 de la primera instantánea de la historia, nos dejó escrito en su tratado «Sur La Practique de la Photographie» (1844), una divertida crónica, no exenta de un cierto aire de sorna y socarronería, de lo que podría ser considerado el primer caso de sugestión y movilización de las masas ante un bien de consumo defectuoso y obstruso exaltado por la publicidad como «una de las últimas maravillas de la ciencia y de la técnica»:

«El Palacio del Instituto fue asaltado por una nube de curiosos en la memorable sesión del 19 de agosto en la que el procedimiento fue definitivamente revelado. Aunque llegué con dos horas de antelación, me vi expulsado de la sala junto a tantos otros como yo. Desde el exterior, permanecíamos atentos, expectantes a todo lo que de la comunicación académica pudiese traslucirse. De repente, uno de los congregados sale muy azorado, y todo el mundo se arremolina en torno suyo para hacerle preguntas. Con aire de sabelotodo contesta que el betún de judea y la esencia de lavanda constituyen el secreto. Se le pide que concrete más acerca de la cuestión, pero como no lo puede hacer, nos vimos todos por un instante reducidos a discurrir en torno al betún y la lavanda. En esto, que la multitud vuelve a rodear otro asistente que sale más contrariado aún que el anterior, y héte aquí que nos dice de golpe que se trata del yodo y del mercurio, sin más comentarios. Finalmente la sesión termina, y el secreto se divulga. Por lo que a mí respecta, corro con premura a comprar el yodo, temiendo por la pronta puesta de sol (...). Posteriormente aplico el mercurio sobre mi placa inclinada cuarenta y cinco grados con respecto al horizonte, tratando de calentar con una lamparilla la cazoleta que la sujeta. El misterio se cumple: he obtenido un cielo azul prusia, sobre casas negras como la tinta (...). Me apresuro a guardarme en el bolsillo la prueba obtenida y corro a casa del señor Lerebours, al que le muestro no sin cierta jactancia mi medallón. Pero la imagen no resulta legible porque ha quedado invertida, y además sus dimensiones exiguas la hacen despreciable en comparación a la 
idea que había sido fijada por el modelo de Daguerre. Ellos habían anunciado la posibilidad de ver las cosas, pero en mi placa no se veía más que un espejo chapado. (...) Pocos días después, las tiendas de ópticas se encontraron abarrotadas de aficionados que suspiraban por un daguerrotipo, y se les podía ver encañonando con sus máquinas a los edificios. Todos querían registrar la vista que se les ofrecía desde sus ventanas. Pero dichosos eran aquéllos que conseguían obtener unas siluetas de los tejados recortados en el cielo. Sin embargo, todos quedaban extasiados ante los tubos de chimenea, contando una y otra vez las tejas y los ladrillos de chimeneas, y se maravillaban de poder ver hasta el cemento entre ladrillo y ladrillo. Es decir, que la prueba más pobre les causaba una alegría indescriptible, tanto que ese nuevo procedimiento parecía haber sido inventado efectivamente para crear maravillas» (Gaudin, 1844; traducción nuestra).

La intención antes de nada al traer aquí tan extensa cita, responde a nuestra intención de no dejar en saco roto la importancia de esta reunión histórica; buena cuenta de ello, lo aporta entre otras curiosidades, el hecho de que entre sus bancos, reservados en tal ocasión para personal selectamente escogido, se encontraba sentado entre otras personalidades de la época, el mencionado Paul Delaroche; maestro de pintores como Gustave Courbet o Jean-FranÇois Millet, cuyas obras a su vez se verán inevitablemente influenciadas por la fotografía -como no podía ser menos.

\section{Talbot y la 'Fotografía Publicada'}

El relevo en este terreno a la técnica descubierta por Nièpce y divulgada tras su muerte con ánimo de lucro y con claros intereses comerciales por Daguerre, vendría de parte de la fotografia inglesa y de los promotores del procedimiento denominado Calotipo o Talbotipo, -término debido a su creador, el inglés William Henry Fox Talbot.

Hombre versado en ciencias físicas y botánicas y doctor en Artes, Talbot combinaría magistralmente ambos conocimientos para alumbrar el actual proceso fotográfico a partir del uso de un negativo, tal como lo seguimos conociendo hoy. Su educación estética y refinada propia de su abolengo aristocrático, junto como su curiosidad científica acerca de las propiedades de las sales de plata, le llevaría a pensar en un método óptimo, duradero y fácil de conseguir imprimir imágenes de la naturaleza directamente sobre papel y sin la intervención de la mano del dibujante -tal como resultaba ser una constante en todos los pioneros de la fotografía.

Las primeras muestras que nos han llegado de sus ensayos, proceden de 1834-35, y son el resultado de intercalar especies distintas de hojas y telas diversas en contacto directo con la luz, sobre un papel previamente sensibilizado con una 
solución de nitrato de plata. Fue así como conseguiría lo que él denominaría sus 'Photogenic Drawings', o dibujos fotogénicos, por medio de los cuales «se consigue que los objetos naturales se delineen por sí mismos sobre el papel» ${ }^{6}$. Tal como le ocurriera a Nièpce, la imagen obtenida aparecía en negro e invertida (en negativo, diríamos hoy), como resultado de la opacidad y transparencia de los propios objetos superpuestos. Sin embargo, y a diferencia de Nièpce, las desahogadas condiciones económicas y de salud, permitiría a Talbot perseverar en sus investigaciones, introduciendo a partir de 1839 dos mejoras sustancialísimas: en primer lugar, las imágenes de Talbot, eran obtenidas directamente de la naturaleza y no se limitaba a reproducir sólo las imágenes previamente dibujada de los grabados. Y en segundo lugar, -y lo que resultaría de trascendental importancia, concibió la posibilidad de revertir el proceso con la intención de obtener directa y automáticamente una imagen igual al original sin necesidad de requerir un proceso de estampación manual. Tal como recogería su biógrafo, desde 1835 ya pensaba Talbot en "lograr hacer transparente al papel del primer dibujo para servir como objeto, produciendo un segundo dibujo en el que luces y sombras quedarían invertidas" (Cf. Arnold, 1977). Esto fue lo que conseguiría en los inicios del año de 1839 utilizando sus propias cámaras oscuras, o ratoneras como él gustaba de llamarlas, sirviéndose para ello de los conocimientos sobre fijación de la imagen que le proporcionara el propio padre del término Fotografía, el científico inglés Sir Hershel.

Pero lo que no podemos dejar de subrayar en estos momentos -tal y como ocurriría en el caso de Nièpce-, es que lo que Talbot consigue a través primero de sus dibujos fotogénicos y por medio de sus calotipos directos después, es introducir la imagen en la impresión y edición de libros ilustrados. Pues a la primera empresa -nunca mejor dicho-, a la que Talbot dedicará sus esfuerzos, después de que en 1843 consiguiera del gobierno británico la patente por su invento, será la difusión seriada de sus negativos con fines lucrativos privados. De su propia industria fotográfica denominada 'Talbotype Establishment', saldrían millares de copias idénticas con vistas a su publicación y divulgación masiva y en formato de libro. El más conocido de estos proyectos lleva por título «The Pencil of Nature», primer álbum razonado de imágenes originales con reseñas y explicaciones sobre las fotografías y su procedimiento concreto, el calotipo. Publicado en Londres en seis entregas, de junio de 1844 hasta abril de 1846, constituye el precedente histórico de lo que consideramos hoy catálogo de fotografías o, -para ser más

6 Talbot aún no convencido con sus resultados postergaría sus experimentos hasta que la publicidad le informaría de los éxitos que en París estaba ganando la daguerrotipia, de un tal Sr. Jacques Mandé Daguerre. El 31 de enero de 1839, Talbot se decide a presentar ante la Royal Society de Londres el informe que recoge sus experimentos con el tituló de: «El arte del Dibujo Fotogénico, o proceso mediante el
se obtiene que los objetos naturales se delinean por sí mismos, sin la ayuda del lápiz del artista». 
exactos-, catálogo de fotografías publicadas. Después de Talbot, William Sterling, publicaría en 1847, su «Annals of The Artists of Spain», libro que introducía por primera vez en la historia de la crítica del arte, fotografías originales (en este caso calotipos) de los maestros de la pintura española. A partir de entonces, podrá hacerse realidad la idea lanzada por André Malraux hacia la consecución de un Museo Imaginario, cuando afirmaba: «La historia del arte es la historia de lo fotografiable» (Malraux, 1950).

Este parecía ser el cometido en Francia del taller de Louis Desiré BlanquartÉvrard, quien conseguiría dar un impulso decisivo a la industria de la fotografía publicada con la introducción por primera vez en el tiraje de copias, del método por revelado químico de la imagen latente, gracias a la introducción del papel albuminizado; lo que permite acortar considerablemente el tiempo de la exposición a la luz solar de los clichés negativos, a la vez que se multiplican por mil el número final de pruebas tiradas al día en un solo taller ${ }^{7}$. Si añadimos el dato histórico, recogido por M-Loup Sougez (1988), de que la idea del uso del papel a la albúmina le llegó a Blanquart-Évard a través de un antiguo ayudante del propio Talbot, podremos establecer con mayor claridad esta primera articulación ignorada de la fotografía con la industria de la imagen seriada, desde los inicios mismos de la génesis del medio. Precisamente, la publicación mejor elaborada de cuantas nos legara la imprenta de Évrard, fue posible gracias al encuentro en Egipto de un pintor metido a fotógrafo (Maxime du Camp), y un escritor que hacía las veces de cronista y comentarista de las imágenes del primero (Gustave Flaubert), entre 1849 y 1852 titulado: "Égipte, Nubie, Palestine et Syrie". (Cfr, Steegmuller, 1972).

5. De las tres modalidades fotopublicitarias en los orígenes del medio: Fotografía Editorial. Propaganda Política. Retrato de Estudio.

Desde la década de los cuarenta, se ven perfilarse ya las tres formas de aplicación que encontrará la fotografía publicitaria en el marco de la construcción de la nueva sociedad contemporánea, para cuyo servicio trabajará ya sin descanso desde entonces. Por un lado, la fotografía publicitaria de aplicación editorial, y cuyo destino por momentos, parecía haber quedado cerrado ante la nueva práctica del grabado heliográfico. Por otro lado la fotografía de propaganda política o institucional, al servicio de los más grandes estados occidentales del momento:

7 Al final del decenio de los cuarenta los fotógrafos-pintores y los partidarios de desarrollar la fotografía según las imperfecciones propias del dibujo, coincidirían en el año de 1851 con dos importantes mejoras técnicas: Gustave Le Gray, en una nota publicada por la propia Academia de Ciencias parisina, anunciaba técnicas: Gustave Le Gray, en una nota publicada por la propia Academia de Ciencias parisina, anunciaba
el uso de cera fundida entre la textura de la superficie de la prueba fotográfica, con el fin de reducir la el uso de cera fundida entre la textura de la superficie de la prueba fotográfica, con el fin de reducir
indefinición de la imagen final. Y ese mismo año, Louis-Desiré Blanquart-Evrard produce en Lille un papel indefinición de la imagen final. Y ese mismo año, Louis-Desiré Blanquart-Evrard produce en Lille un papel
que -a diferencia de los de ennegrecimiento directo-, reactiva la formación de la imagen latente de manera que -a diferencia de los de ennegrecimiento di
acelerada bajo la acción de agentes químicos. 
Estados Unidos, donde el daguerrotipo se encontrará más cómodo que en ningún otro lugar, llegando a perdurar hasta finales de la década de los setenta. Y el caso francés, donde el daguerrotipo triunfará al servicio de las campañas de documentación del patrimonio expoliado, como será la gran Mission Heliographique. Y por último el caso más celebrado y esperado por todos: la fotografía de retratos, la cual ofrecía por primera vez, la posibilidad de disponer de un retrato realista, rápido, y efectivo para todo el mundo, -desde el burgués, hasta el proletariado.

\subsection{El Daguerrotipo y los orígenes de la Fotografía Editorial}

La Fotografía Tanto J. Mandé Daguerre y su incipiente industria comercial, así como Henry F. Talbot, dedicado a la documentación del patrimonio biológico, intentaron ambos siempre, y por todos los medios, aumentar las posibilidades de la mirada del nuevo dispositivo, en tanto que sistema de registro capaz de mostrarnos el mundo tal como se aparecería a los ojos del hombre si éste pudiese ver más allá del espectro visible. Exploración y colonización visual que se inicia en el ámbito de lo macroespacial -el telescopio que se mandara construir Daguerre para fotografiar la luna- así como en el ámbito de lo microespacial -los 'Photogenic Drawings', de Talbot, y su interés por la vida en el orden de lo microbiológico. Este interés documental por todo lo orgánico e inorgánico existente sobre la faz de la tierra, irá dando paso silenciosamente en el ámbito de la representación, a una nueva inclinación estética que pareció conformarse con la revelación de la verdad que se esconde detrás de cada uno de estos fragmentos. Es así como puede cerrase el círculo sobre una primera práctica fotográfica en el siglo XIXEs así como puede cerrase el círculo sobre una primera práctica fotográfica en el siglo XIXEs así como puede cerrase el círculo sobre una primera práctica fotográfica en el siglo XIXas' como puede cerrase el c'rculo sobre una primera prłctica fotogrłfica en el siglo XIX: el documentalismo, como método correcto de aproximación a la imagen fotográfica, en tanto que herramienta que debía servir exclusivamente para la reproducción detallada y cuidada de aquello que el artista sólo podría conseguir, «con gran imprecisión de detalles, y en muchísimo más tiempo» (Delaroche, 1839); y donde el interés documental muestra de manera reveladora la influencia que inspirará a la fotografía por encontrar un lenguaje y una estética propios. Sería el propio Talbot, quien con más claridad quizás intuyó algo de esta sintió cuando escribía en su «Pencil of Nature»:

«Sucede frecuentemente además, y éste es uno de los encantos de la fotografía, que el operador de la cámara mismo descubre al examinar la obra, tal vez después de transcurrido mucho tiempo, que ha captado muchos detalles que ignoraba inicialmente. Se encuentran a veces inscripciones y fechas en los edificios, o carteles impresos sobre las paredes de lo más irrelevante. A veces, se percibe en un cuadrante la distancia y sobre éste, 
inscrita inconscientemente, la hora del día en que se tomó la vista [...]. Una ventaja del descubrimiento del Arte Fotográfico será el permitirnos introducir en nuestros cuadros una multitud de minúsculos detalles que se sumarán a la veracidad y al realismo de la representación (...). Sin embargo, está bien tener a nuestra disposición los medios para introducir estas minucias sin esfuerzo adicional, pues descubriremos que éstas, a veces, dan a la escena representada un aire de variedad más allá de lo esperado» (Talbot, 1844).

Sin embargo, Talbot decidió continuar en los últimos años de su vida dedicado a promocionar la industria de la fotografía publicada, de espaldas a la gran industria del retrato que comenzaba a configurarse en torno al comercio de los primeros daguerrotipos vendidos por Daguerre y su cuñado Giroux. Empresa, para la que tampoco conseguiría gran reconocimiento, pues pronto el daguerrotipo se subiría al tren del procedimiento de la reproducción heliográfica, con el fin de poder ser divulgado a través los periódicos ilustrados, así como a través de las páginas de las primeras publicaciones dedicadas a la fotografía. Millares de aficionados se aprestaban a tomar daguerrotipos que luego eran enviados a los editores con el fin de conseguir los beneficios económicos de su reproducción heliográfica. Desde el primer lustro de la historia de la fotografía, el daguerrotipo conseguiría pronto allanar este camino a través de las investigaciones de Alfred Donné primero (1839-40); mediante Louis Poitevin después (1840-41); y sobre todo, a través de las vistas y grabados obtenidos por Louis Fizeau entre 1841 y 1844, y publicadas por el editor Lerebours bajo el título de «Excursiones Daguerrinianas". El procedimiento retoma literalmente en estos momentos el destino anunciado ya en los tiempos de Nièpce, y puede ser visto como el momento del inicio, a escala comercial, de la industria de la fotografía editorial que terminará atrayendo bajo su influjo a toda la práctica de la ilustración seriada.

Posteriormente, ya en la década de los cincuenta, se crea la Sociedad Heliográfica (1851), bajo el pretexto -según su principal promotor, el editor Ernest Lacan-, de llevar a la fotografía por el camino que le pertenecía, y que no debía ser otro que el de «servir ante todo a los intereses de los fotógrafos, y que no es otro que el de facilitar la venta de sus obras» (Cit, en: Lemagny \& Rouilé, 1981: $34)^{9}$. Por ello, no resulta extraño que los primeros pasos de la historia de la fotografía vayan de la mano de la impresión fotográfica y el de conseguir un

9 El pensamiento y la intitulación adoptada tanto para su primera institución, como para su revista, resultan altamente coherente con los orígenes embrionarios del procedimientos, pues -como se verá de inmediatolos primeros ensayos para impresionar imágenes múltiples y sin la intervención aún de la cámara oscura, se la debemos al francés Jean-Nicèphore Nièpce, el cual obtuvo desde 1817 y hasta 1821 al menos, dibujos se la debemos al francés Jean-Nicèphore Nièpce, el cual obtuvo desde 1817 y hasta 1821 al menos, dibujos
por contacto directo a partir de grabados sobre papel encerado, a lo que dio el nombre de «dibujos por contacto 
método que facilitase la ilustración de libros mediante documentos fotográficos. En 1855 se expone en París la segunda Exposición Universal que viene a dejar constancia de esta situación anunciada desde 1851 a través de dos adelantos técnicos: por una parte, la estereoscopía y, sobre todo, la aparición por primera vez de una superficie intermedia -el colodión-, que se interpone entre el soporte de base usado y las sales de plata fotosensible, a fin de conseguir mayor nitidez, consistencia y permanencia de la prueba. Y por otra parte, la consagración del grabado heliográfico, como sustituto del negativo fotográfico para la estampación de copias destinadas a la ilustración de libros y periódicos. A partir de entonces, el influyente Ernest Lacan señalará que, "la fotografía, por completos que sean sus resultados, no es más que un procedimiento transitorio, cuyo porvenir pertenece al grabado heliográfico o a la fotolitografía (...), que tienen la enorme ventaja de adaptarse a las condiciones de la imprenta" (Lacan, 1856).

Ese mismo año, la Sociedad para la Fotografía Francesa (SFP), recientemente creada en 1855 tras la disolución de la Sociedad Heliográfica, organiza un concurso para sustituir los halogenuros de plata por otras sustancia más permanentes que garanticen la inalterabilidad de los clichés. Esto fue lo que conseguiría finalmente Alphonse Poitevin en 1862, con la introducción del carbón, como materia inerte, lista para estampar. A partir de entonces, el desarrollo en las técnicas de la estampación del texto ilustrado vendría del respaldo económico recibido por la industria del fotograbado. El primer fotograbado sobre plancha de cinc se consigue en 1876, por obra de Charles Guillot. Con este sistema se consigue desplazar definitivamente a la xilofotografía (madera fotosensibilizada), de Thomas Bulton. Sin embargo, los clichés de Guillot no permitían reproducir los trazos o degradaciones tonales, borrando del dibujo los medios tonos o las degradaciones de semitonos entre un trazo de línea y otra. la solución a este problema vendría de la mano del alemán Meisenbach, quien interpuso entre la fotografía y el cliché una retícula de puntos variada según su densidad, que permitían reproducir las degradaciones tonales del original.

Los primeros fotograbados habían sido tirados por el rotativo inglés 'The Illustrated London News', con ocasión de las imágenes de la Guerra de Crimea cubierta por Roger Fenton en 1855. Sin embargo, en estos momentos la técnica embrionaria de la reproducción fotomecánica, todavía sobre madera, hacía que las publicaciones finales de las fotografías se devieran antes que a la cámara de Fenton, a un producto imaginativo del dibujante grabador que se veía implicado en el proceso de retoque y corrección de las pruebas, que imperfecciones derivadas de la transferencia fotográfica al taco de madera. La primera imagen fotográfica sin retocar, se debe a un nuevo sistema ideado por Meisenbach, aparecido el 4 de marzo de 1880, en el rotativo 'Daily Graphic', de New York. Mientras que el primer diario que apuesta por el uso sistemático de la foto tramada acompañando al texto, es el inglés 'Daily Mirror', desde 1904. 
A partir de entonces, se iniciaría el despegue definitivo de las primeras revistas ilustradas especializadas en la reproducción de imágenes fotográficas; de tiradas más limitadas, y dirigidas a un público más elitista, debido a lo costoso de su técnica. Situación que terminaría divulgándose finalmente hacia finales de la década de los treinta, con la introducción masiva del sistema 'Offset' en las rotativas del mercado editorial. Técnica ésta última que posibilitaría la aparición de la revista ilustrada, soporte indispensable para el desarrollo de una fotopublicidad moderna. En 1928 el editor francés funda $V u$, y en Norteamérica Henry Luce funda Life (1936), auténticas pioneras mundiales del género fotopublicitario de difusión editorial.

\subsection{La Fotografía Institucional}

De las tres modalidades fotográficas que comienzan a descollar con el uso del daguerrotipo, la que contará desde el principio con más respaldo económico e institucional por parte del gobierno francés será la fotografía de patrimonio, para cuyo fin parecía estar reservado el futuro de la fotografía:

«Con el daguerrotipo un solo hombre podrá llevar a buen fin este inmenso trabajo. Suministrad al Instituto Egipcio con dos o tres aparatos de M. Daguerre, y a partir de las grandiosas y célebres obras artísticas, vastas extensiones de jeroglíficos serán remplazadas por jeroglíficos ficticios o puramente convencionales, fruto de nuestra inmortal expedición... Y todo el mundo se percatará del inmenso papel a desarrollar que le ha sido destinado al proceso fotográfico» (Aragò, 1839; En: Frizot, 1987: 12; traducción nuestra) ${ }^{10}$.

La primera aceptación social y sin compromisos que se le ofreció a la fotografía sería la de servir de testimonio fidedigno y objetivo de las expediciones realizadas hacia Oriente -en el caso de Gran Bretaña, principalmente- y hacia Tierra Santa y norte de África -en el caso francés. Y como quiera que este interés

10 El texto de Aragò nos sitúa ya ante el primer intento de documentación gráfica de patrimonio que se realiza en Europa: las célebres campañas de captación fotográfica de los monumentos egipcios durante la dominación francesa, y en las que participará el mismo Flaubert. Esta misma inclinación colonial fue auspiciad por principales los escritores de la época, desde Mallarmé y Byron, hasta Flaubert y Maxime du Camp, ta como queda documentado por las imágenes y las notas que estos dos últimos tomaron durante su viaje de reconocimiento por Egipto a partir del otoño de 1849: «Me parece casi imposible que dentro de poco Inglaterra no se adueñe de Egipto (. ) todo el mundo quedarí parece casi imposible que dentro de poco Inglaterra no se adueñe de Egipto (...), i. a la primera señal de disturbios en Europa, Inglaterra invadirá Egipto, Rusia invadirá Constantinopla (...). Aquí no hay nada que impida una invasión. (...) En lo que respecta a la masa árabe, no le interesa para nada saber a quién pertenecerá. Con diferentes nombres, siempre será la misma y no ganará nada porque Sensibility on Tour»] 
por documentar el mundo conocido (etnocentrismo), y por domeñarlo (colonialismo), necesitara del respaldo de los pueblos hacia sus dirigentes y sus ejércitos, la primera aceptación social y sin compromisos que se le ofreció a la fotografía sería la de servir de testimonio fidedigno y objetivo de las expediciones realizadas.

A partir de entonces, la curiosidad albergará a millares de buenos aficionados, connaisseurs français, que extenderán su mirada, mediante el uso indiscriminado del objetivo fotográfico, sobre cualquier resto arqueológico o de interés cultural: Goupil y Horacio Vernet en Egipto, desde 1839; el barón Gros en Colombia, desde 1842; Jules Itier en China desde 1843; du Camp en Tierra Santa, desde 1845. Conseguidas al hilo de las campañas de documentación del patrimonio histórico-artístico que inician las principales potencias occidentales en su disputa por la patente de la nueva técnica de representación (Francia, Gran Bretaña y Estados Unidos), desde la «Mission Heliographique, desarrollada en el siglo XIX en las colonias francesas, hasta el «Rephotographic Survey Project» y la «Farm Security Photographic Project», durante los tres primerios decenios del siglo XX, -sin olvidar las campañas de apropiación visual y expropiación colonial llevada a cabo por todo el oeste norteamericano.

A pesar de las reclamaciones de los principales fotógrafos ${ }^{11}$, por llamar la atención hacia las potencialidades del medio como vehículo de expresión artística, sus virtudes en estos momentos servían sólo al interés documental y explorador puesto al servicio de los gobiernos, que veían así colmados sus deseos de conocer el mundo allende sus propias fronteras. Vocación de registro objetivo que se materializa con el desarrollo inmediato de su primera industria: el retrato de estudio; y una nueva práctica científica: el desarrollo de la documentación fotográfica con el uso incondicionado de la cámara fotográfica, a partir de las expediciones de viajes a las tierras colonizadas por la hegemonía occidental -desde Flaubert, hasta Capra. Orígenes obligados a su vez, del primer fotoperiodismo -desde los americanos Mathew Brady y Lewis Hine, en el XIX; hasta los europeos Erich Salomon y Felix Man, en el XX. No en vano, la primera exposición dedicada en exclusiva a la fotografía, en diciembre de 1852 en la "Society of Artists" de Londres, fue exhibida como una muestra de fotografías de viajes que daban buena fe de los documentos etnográficos procedentes del mundo de las colonias.

Exploración y colonización visual que se inicia en el ámbito de lo macroespacial -el telescopio que se mandara construir Daguerre para fotografiar la luna- así como en el ámbito de lo microespacial -los 'Photogenic Drawings', de Talbot, y su interés por la vida en el orden de lo microbiológico. Tanto J. Mandé

11 A este momento pertenecen los aislados y esporádicos gritos de alarma en favor de un arte fotográfico: (Le Gray, Gustave, 1850: «Traité Pratique de la Photographie»; así como Blanquart-Évrard, 1855), por citar dos de los más relevantes fotógrafos del momento. 
Daguerre y su industria, la tradición de los retratos (Disdèri: 1862), y las fotos de documentación de patrimonio, verdaderos precedentes de nuestros álbumes de familia y de viaje ${ }^{12}$ respectivamente, así como Henry. F. Talbot, dedicado a la documentación del patrimonio biológico, intentaron ambos siempre, y por todos los medios, aumentar las posibilidades de la mirada del nuevo dispositivo, en tanto que sistema de registro capaz de mostrarnos el mundo tal como se aparecería a los ojos del hombre si éste pudiese ver más allá del espectro visible.

Esta misma necesidad de redescubrimiento visual del mundo que el positivismo impone al medio, será también la causante de las continuas mejoras químicas y ópticas que se van sumando con la sola intención de mejorar su calidad reproductora, sobre todo en la consecución de un mayor grado de iconicidad en lo referente a color y volumen ${ }^{13}$. Como puede fácilmente colegirse del último texto arriba citado, el uso de la fotografía como herramienta de documentación gráfica quedaba por encima de cualquier duda y había de primar ante cualquier empeño conceptual por introducirla por la puerta grande de los Salones de las Bellas Artes parisinos. Oigamos una vez más en este punto, al propio Baudelaire declamando acerca de la multitud, acerca del público moderno:

«(...) Que enriquezca con rapidez el álbum del viajero y preste a sus ojos la precisión que faltaría a su memoria, que adorne la biblioteca del naturalista, que exagere los animales microscópicos, que corrobore, incluso con algunas pruebas, las enseñanzas del astrónomo; que sea en fin, la secretaria y el archivo de quien necesite en su profesión de una exactitud material absoluta. Si salva del olvido las ruinas correspondientes, los libros, las estampas y los manuscritos que devora el tiempo, las cosas preciosas cuya forma va a desaparecer y que exigen un lugar en los archivos de nuestra memoria, entonces se le agredecerá y aplaudirá» (Baudelaire, 1868; En: Frizot, 1987: traducción nuestra).

12 Uno de estos primeros álbumes resultará famoso por un doble motivo: por un lado, sus imágenes acompañadas de prosas y versos, recogían el ambiente romántico de los exiliados franceses refugiados en la isla de Jersey, a raíz del golpe de Estado de Napoleón III; y por otro lado, su autor resultaba ser Víctor Hugo. La tradición de los álbumes de familia llegará a su máximo desarrollo, a partir del uso del papel la albúmina, procedimiento con el que se inicia la práctica de añadir música a los álbumes más ricamente ornados. Lo que hará de ellos, al incluir imagen, texto y sonido, una nueva variante del espectáculo audiovisual público, tan característico en el París de fin de siglo, simultáneo a los Dioramas y Panoramas de Daguerre, y anterior a los Cinematógrafos de los Lumière.

13 Desde los primeros intentos pigmentarios por reproducir el color efectuados en los años sesenta por Charles Cros y Ducos, inspirándose en las investigaciones científicas de Young y Maxwell, y el Autocromo lanzar por los hermos Lumière; y por último el procedimiento sustractivo Kodaxwell, y el Autocromo lanzado por los rection palace, hasta la holografía de Dennis Gabor, a mediados de nuestro siglo (Cf, Ramírez, 1988: 96-97). 
Sin embargo, este interés documental por todo lo orgánico e inorgánico existente sobre la faz de la tierra, irá dando paso silenciosamente en el ámbito de la representación, a una nueva inclinación estética que pareció conformarse con la revelación de la verdad que se esconde detrás de cada uno de estos fragmentos. Visión, que quedará constatada en la práctica fotográfica, desde el momento en que Nadar se suba a un globo para fotografiar la tierra desde las alturas. Nueva estética -documentalista, pues-, propulsada por la aereofotografía como nuevo sistema de registro documental emprendida por Félix Nadar, desde 1858, tomando vistas de París -como ya hemos visto-; pero también por James W. Black, sobrevolando Boston, desde 1860; así como, en el siguiente siglo, por el propio creador de la Leica, Oskar Barnack, sobrevolando Wetzlar desde 1913; y por último, las fotografías aéreas utilizadas por Malevich en su «Mundo no Objetivo», de 1927. Y donde el interés documental muestra de manera reveladora la influencia que inspirará a la fotografía por encontrar un lenguaje y una estética propios.

Es así como puede cerrase el círculo sobre una primera práctica fotográfica en el siglo XIXEs así como puede cerrase el círculo sobre una primera práctica fotográfica en el siglo XIXEs así como puede cerrase el círculo sobre una primera práctica fotográfica en el siglo XIXas' como puede cerrase el c'rculo sobre una primera prłctica fotogrłfica en el siglo XIX: el documentalismo, como método correcto de aproximación a la imagen fotográfica, en tanto que herramienta que debía servir exclusivamente para la reproducción detallada y cuidada de aquéllo que el artista sólo podría conseguir, «con gran imprecisión de detalles, y en muchísimo más tiempo» (Delaroche, 1839). Será esta misma práctica de la documentación de patrimonio, en tanto que práctica alentada desde las arcas de los estados coloniales, la que podamos situar a la cabeza de las primeras fotografías de propaganda política e institucional. No es casual, en este sentido el interés despertado por estadistas y personalidades públicas de los Imperios occidentales, ante el poder de sugestión del retrato fotográfico: Abraham Lincoln afirmaría tras su elección como presidente, que se lo debía en gran parte a la fotografía de Mathew Brady, y a todo su equipo de fotografía de reportaje. Y por parte del II Imperio Francés, Luis Napoleón Bonaparte no podía ocultar su apego hacia la fotografía, por cuanto uno de los principales estudios de fotógrafos de retrato en Francia, el de los hermanos Meyer et Peirson, disfrutaba del título de estudio de fotografía oficial del propio emperador. Puede recordarse por último en este apartado dedicado al uso servilista del medio con fines de propaganda o de instrucciones judiciales, el acontecimiento de la Comuna francesa (1871), en el que por primera vez se consigue implicar falsamente a unos personajes, mediante el retoque y la falsificación de la realidad que puede llevarse a cabo desde la fotografía. 
5.3. Éxito y apogeo del Retrato de estudio fotográfico

A partir de los años cincuenta, y con la implantación definitiva de los primeros talleres de fotógrafos profesionales afincados en las calles de las emergentes metrópolis del orbe occidental, aparece la primera gran industria, y con ella el primer género eminentemente fotográfico: el retrato de estudio.

La misma necesidad de redescubrimiento visual del mundo que el positivismo había impuesto sobre al medio, será también la causante de las continuas mejoras químicas y ópticas que se van sumando con la sola intención de mejorar la calidad reproductora de la imagen del sujeto, sobre todo en la consecución de un mayor grado de nitidez en lo referente a su autorreconocimiento. Ante los objetivos de los daguerrotipos aparecía ahora una nueva topografía, la de la arrugas y verrugas de la faz del hombre, en pie de igualdad y de importancia con la topografía geográfica de la faz de la tierra descubierta por los gobiernos británicos y franceses.

El siglo XIX, así como ocurrió a lo largo de su precedente más directo, el Quattrocento italiano, será un periodo caracterizado por el relanzamiento por igual de los géneros artísticos del paisaje (urbano), y del retrato (burgués). Pero, con el ascenso a las ciudades del nuevo proletariado industrial surge una nueva demanda -social a la par que absolutamente existencial- como iba a ser la de conseguir fijar la imagen del nuevo héroe trabajador que coadyuva con el burgués en la construcción de la nueva sociedad contemporánea. De la misma forma que el hombre renacentista era captado en tanto que individualidad física, tangible y sobre todo, visible; el nuevo hombre decimonónico surgido a expensas de las convulsión industrial revolucionaria, recobrará su interés político y social en tanto que nueva persona -jurídica, además de política-, plena de derechos y capacitada para reclamar para sí una nueva imagen a su medida y semejanza. Pero a diferencia del retrato renacentista, el retrato fotográfico de la masa del nuevo público moderno, surgirá en tanto que agente productor de su fuerza de trabajo. Por lo que los primeros retratos tenderán a desarrollar el papel del personaje propio que cada cual representa en el terreno de la construcción industrial de la cultura contemporánea. Será en el contexto narrativo de su actuación como actor distinguido (intelectual o científico), o como actor anónimo (trabajador), donde surjan los primeros intentos por concretar la nueva individualidad del hombre libre, recién salido del marco constreñidor del 'ancien régimen'.

La primera función comercial que se obtiene del oficio de fotógrafo se derivará por ende de esta fotografía de retrato, cuyos escasos estudios y profesionales a finales de la década de los cuarenta, constituirán el caldo de cultivo sobre el que fructificará todo tipo de innovaciones y mejoras tecnológicas.

La vinculación del retrato con la fotografía de publicidad resulta hoy innegable, máxime cuando existe hoy un tipo de fotografía publicitaria -la foto de moda-, cuyo código se rige por el culto ciego al rostro y al cuerpo humanos. Pero 
lo que resulta aún más interesante para la línea de nuestro proyecto historiador, es que las primeras intervenciones de manipulación y arreglos del original se constatan en el origen mismo de la práctica del retrato de estudio. En efecto, la práctica tan corriente hoy de retocar y embellecer mediante puntos de luz, o por medio de tratamiento digital la fotografía de publicidad, se constata en la prehistoria del medio desde el momento mismo en que surgen los primeros retratos al daguerrotipo. En los primeros estudios, debido a la baja sensibilidad de los materiales empleados, los sujetos habían de permanecer posando durante minutos atados por escondidos corsés que evitaban que los rostros y las manos salieran movidos.

A partir del decenio de los cincuenta, se inicia una nueva fase en la historia de la fotografía, caracterizada por la extensión comercial del primer oficio fotográfico: el retrato de estudio. Fue así, como la primera aceptación social de la fotografía en el ámbito doméstico y de uso familiar pasaría por la documentación del rostro y el nuevo individuo que comienza a cristalizar en los inicios de la era contemporánea, relegando el resto de prácticas fotográficas para la documentación de paisajes y lugares exóticos. Tenemos así dos prácticas bien diferenciadas surgidas ya en la década de los cincuenta, una vez la fotografía ha conseguido superar las improvisaciones e inconsistencia de su técnica.

Por una parte, la documentación del rostro y la figura humana, para la cual se desarrolla la técnica concreta del 'Colodion' (Frederick Scott Archer, 1851) ${ }^{14}$, con la que se obtienen tres ventajas sustanciales: por un lado, se gana en espectro lumínico para la sensibilización de las pruebas; por otro lado, se reducía considerablemente el tiempo de exposición, desde un par de minutos a lo sumo, hasta decenas de segundo en los casos de máximas condiciones lumínicas. Y en tercer lugar, la superfice de colodión actúa de capa intermedia entre los haluros de plata y la superficie porosa y maleable del negativo, con lo que se gana en definición y nivel de nitidez de la copia final. Todas estas mejoras del colodión terminarán desbancando al daguerrotipo, y su uso se mantendrá, a excepción de los Estados Unidos, en la práctica totalidad de la fotografía de retratos hasta la década de los ochenta.

Conclusiones finales -necesariamente provisionales-.

En verdad el análisis llevado a cabo por nosotros hasta aquí en pos de unos orígenes embrionarios de la fotografía publicitaria, ha querido empezar por aquello

14 El procedimiento al 'Colodion' que en breve desbancaría al resto de los sistemas de fijación fotográfica de la imagen, se publica por primera vez en la revista científica inglesa, The Chemist, en el número de marzo de 1851. Sabemos que anteriormente, otros fotógrafos -como es el caso del propio G. Le Grayhabían hecho intentos con este mismo material para la consecución de la imagen, pero ninguno, que se sepa, consiguió resultados definitivos como los que ahora presentaba el escultor inglés Scott Archer, a sepa, consiguió resultados definitivos como los que ahora presentaba el escultor inglés Scott Archer, a
quien le sobrevino la idea en un intento por mejorar la calidad de la imagen de los modelos que el quien le sobrevino la idea es
fotografiaba para sus retratos. 
que le resulta paradójicamente más lejano: las prácticas de la fotografía de retrato (de documentación social), y de paisaje (documentación del patrimonio). Pero esta mirada centrada en el documentalismo como germen del trabajo fotopublicitario, lo que podría parecer a primer golpe de vista una contradicción. Sin embargo, dicha actitud se justifica en primer lugar, porque con ello pretendemos atajar con mayor seguridad una investigación global en torno a las bases históricas y metodológicas de la fotografía en su conjunto.

Si nosotros aquí, hubiéramos pretendido una aproximación fácil al tema de la manipulación de la imagen fotográfica en el siglo XIX, no hubiéramos tenido más complicación que extendernos con soltura en las distintas prácticas de embellecimiento y de ocultación del dispositivo fotográfico que llevan a cabo los distintos movimientos estéticos del siglo XIX que conciben a la fotografía como arte, así como sus distintas vinculaciones formales con el arte coetáneo: desde el pictorialismo y el prerrafaelismo inglés, hasta el naturalismo académico, el realismo, o el impresionismo francés, -por citar sólo los casos más evidentes de un uso formal antes que documental del contenido de la fotografía. Ahora bien, por este camino sólo hubiéramos encontrado una reafirmación obvia de lo que resulta inmanente a la propia hipótesis de la que se parte, y nuestro trabajo resultaría entonces un mero caminar hacia la búsqueda de lo que previamente ya sabemos nos debe conducir el camino que hemos tomado.

Pero si hemos emprendido un camino inverso; es decir, intentando rastrear no tanto en las claves significantes o expresivas de la imagen, cuanto que en el propio contenido informativo de la fotografía, ha sido por lo tanto, movidos por la convicción de que de esta forma nuestros hallazgos nos servirían para ponernos sobre la pista no ya de una mera confirmación de lo previamente anunciado, cuanto que ante lo que podría constituir ya las bases comunes a ciertos aspectos inmanentes a la práctica fotográfica química de todos los tiempos.

Nos referimos en definitiva, para no dilatar más las explicaciones en este punto final, a la necesidad de concebir a la fotografía (del siglo XIX, pero también en el siglo XX), como una práctica necesariamente referencial, que debido a su alto nivel de resolución icónica o, -para decirlo en términos más claros-, de nitidez y de definición analógica de la imagen, comporta necesariamente la importancia del contenido informativo de la misma. Inmanencia referencial, que aprovechará la fotografía publicitaria, para hacer olvidar los códigos retóricos de composición y de embellecimiento que el fotógrafo consigue imponer, y ocultar, tras la aparente literalidad que comporta la imagen fotográfica. Por ello, será este alto poder de revelación de la realidad, lo que venga a ser aprovechado por el resto de las prácticas significantes observables en el desarrollo histórico del medio, desde la temprana fotografía de moda y de publicidad, desde principios del siglo XX, hasta las últimas experimentaciones en torno a la fotografía de creación, en nuestros días. 
Pues no debemos olvidar que si en algo está afianzada la confianza y la seguridad del éxito garantizado de los anunciantes y de los fotógrafos de publicidad contemporáneos, es en el alto grado de verosimilitud y de realismo que guarda la imagen fotográfica con el mundo conocido y reconocido por nuestros ojos. Los anunciantes lo saben bien, y aprovechan esta confianza ciega del consumidor o del espectador de la imagen fotográfica, para mostrar no sólo lo creíble, sino también lo increíble fotográfico. Increíble, en la doble acepción contradictoria de este término: esto es, en tanto valor enfático de máximo realismo añadido a la credibilidad de la imagen; pero increíble también, en tanto que responde a una imagen litrealmente falsa (y por ello increíble) de lo realidad cotidiana.

A lo largo de la historia del medio, la fotografía ha jugado con esta doble adscripción treminológica y conceptual, para primar en unos determinados contextos (de ficción) un uso formativo -más cercano a lo publicitario; mientras que en otros momentos de su devenir histórico, el contexto (documental) imponía un uso informativo -más cercano a lo periodístico. Nuestra intención aquí por lo tanto ha consistido en intentar demostrar el funcionamiento de esta estrategia propia de la imagen fotográfica, a partir $-\mathrm{y}$ aquí radica la justificación de la metodología llevada a cabo por nosotros en este trabajo-, de una inversión lógica de las prácticas comunes asignadas a la cronología oficial del medio. De esta forma, si a lo largo del artículo se llega a demostrar la existencia de unas prácticas publicitarias fotográficas, a partir sólo de su vinculación a la imagen de lo referencial propia del siglo XIX, se habrá conseguido también, -y ésta sería nuestra aspiración más importante aquí-, desvelar y desnudar la existencia de esta doble ambivalencia que conlleva toda imagen fotográfica, a partir de su adscripción a lo real captado y registrado por el objetivo de una cámara. 


\section{Bibliografía manejada}

- BENJAMIN, WALTER (1931): Pequeña historia de la Fotografía. En, Discursos Interrumpidos I. Madrid: Taurus, 1989.

- CENTRE NATIONAL DE LA PHOTOGRAPHIE (CNP, 1983): Nicéphore Nièpce. Paris: Ministère de la Culture et de la Comunication.

- DAGUERRE, LOUIS JACQUES MANDÉ (1839): Historia y descripción de los placeres del Daguerrotipo y del Diorama. Palma de Mallorca: Miquel Font Editor, 1991 (Edición Fascímil).

- FONTCUBERTA, JOAN (1984): Estética Fotográfica: una selección de textos. Barcelona: Blume.

- FREUND, GISÈLE (1965): La Fotografía como documento social. Barcelona: Gustavo Gili, 1986.

- FRIZOT, MICHEL (COMP, 1987): Du bon usage de la Photographie: une antologie de textes. Paris: Ministère de la Culture et de la Comunications.

- GERSHEIM, HELMUT \& ALISON, (1966): Historia Gráfica de la Fotografía: una historia concisa de la fotografía. Barcelona: Omega, 1967.

- NEWHALL, BEAUMONT (1973): Historia de la Fotografía: desde sus orígenes hasta nuestros días. Barcelona: Gustavo Gili, 1983.

- POHLMANN, ULRICH (1993): Apuntes sobre la fotografía inglesa del siglo XIX. En, Catálogo de la exposición. Museo del Prado, mayo-junio/93. Madrid: Ministerio de Cultura.

- RAMÍREZ, JUAN ANTONIO (1989): Medios de masas e Historia del arte. Madrid: Cátedra.

- ROUILlÉ \& LEMAGNY, (1982): Historia de la Fotografía. Madrid: Alcor, 1989. 